\title{
Review \\ Clinical review: Mass casualty triage - pandemic influenza and critical care
}

\author{
Kirsty Challen, Andrew Bentley, John Bright and Darren Walter
}

University Hospital of South Manchester NHS Foundation Trust, Manchester, UK

Corresponding author: Kirsty Challen, kirsty.challen@smtr.nhs.uk

Published: 30 April 2007

This article is online at http://ccforum.com/content/11/2/212

(c) 2007 BioMed Central Ltd
Critical Care 2007, 11:212 (doi:10.1186/cc5732)

hospitalisation and 65,000 (7.5\%) will require ventilation. They also outline a "severe" 1918-like scenario with 9.9 million hospitalisations and 743,000 patients requiring ventilation [3].

An influenza pandemic will undoubtedly create a major increase in demand for critical care services. The majority of UK hospital intensive care units (ICUs) are already operating at $>98 \%$ bed occupancy. Integral to the success of any emergency planning strategy is 'surge capability', incorporating the ability to scale up the delivery of appropriate specialist care to those that require it [4]. Modelling of the impact of an influenza pandemic on UK critical care services has been carried out using the FluSurge 1.0 programme developed at the US Centers for Disease Control [5]. With simulation of an 8-week epidemic and 25\% attack rate the demand for critical care beds from patients with influenza would represent 208\% of current combined level 2 (highdependency unit) and level 3 (ICU) bed capacity, and 231\% of current level 3 capacity [6]. Even allowing for optimistic estimates of other modulating factors (50\% reduction in ICU demand with use of neuraminidase inhibitors and $50 \%$ upgrade of level 2 to level 3 beds), level 3 bed occupancy due to the pandemic would remain at $75 \%$. Furthermore, occupancy of level 3 beds by 'flu patients' was unsustainable at approximately $50 \%$ in terms of care for other patients even in the most optimistic conditions.

Although some research and modelling exists regarding hospital surge capacity for major incidents, this generally relates to 'big bang' single incidents rather than 'rising tide' prolonged problems [7-11]. The closest objective evidence for efficacy of critical care in the event of a flu pandemic is extrapolated from $\mathrm{H} 5 \mathrm{~N} 1$ influenza and the recent SARS outbreak in Toronto. Of the H5N1 admissions to hospital in Thailand, 75\% developed respiratory failure. Hospital mortality in these cases was $75 \%$ [12]. During the Toronto

$\mathrm{ICU}=$ intensive care unit. 
SARS outbreak, up to $32 \%$ of cases were admitted to ICU, $25 \%$ were mechanically ventilated and 28 day mortality for ventilated patients was $45 \%$ [13]. In Singaporean SARS patients admitted to ICU, 98\% developed ARDS [13].

Properly constructed plans for the delivery of critical care during an influenza pandemic must include the ability to deal with excessive demand, high and possibly extreme mortality, and the risk to the health of critical care staff.

\section{Incident management and surge capacity}

The consequences of a pandemic, both in terms of numbers of patients and the effect on the healthcare system, are likely to precipitate a 'major incident' where special arrangements are needed to manage the system while it is under extreme pressure. It is anticipated that there will be an overwhelming demand for critical care services, not only for respiratory support through mechanical ventilation but also for a full range of care to manage multi-organ failure. Assuming that the next pandemic derives from the H5N1 strain, the epidemiological evidence to date suggests extremely high mortality and, although not precisely quantifiable, a significant risk to health care workers. Both of these will undermine the ability to deliver critical care to influenza patients even before consideration is given to the duty of care to other critically ill patients.

Coherent incident response requires a robust command and control structure, with the ability to make rapid informed decisions across an organisation and also across a health economy. In the UK, health incident management is based on a 'medallion' structure, with gold, silver and bronze corresponding to strategic, tactical and operational command levels [14]. North American and Asian health institutions tend to use the Hospital Emergency Incident Command System [15]. The common theme in both systems is a clear command and control structure with which healthcare staff should be familiar [4,14,16-19]. Their generic hierarchical structure allows application to a wide range of incidents whilst retaining familiarity gained from training and exercises. The importance of familiarity with the command and control structure was highlighted in a recent Delphi study [20] and European survey [21].

Critical care contingency planning guidance from the UK Department of Health places an expectation on providers to expand their level 3 bed capacity by a factor of 3 but no more. Provision of full multiorgan level 3 support is recognised to be unrealistic, but principally respiratory support is felt to be achievable. Cancellation of elective surgery to minimise alternative sources of demand for critical care, upgrading level 2 to level 3 facilities and recruitment of theatre recovery areas and even operating theatres may allow expansion of ICU-like care capacity. Staff in these areas already have the competencies to manage sedated patients and those receiving respiratory support. Escalating their clinical role should require relatively limited focussed training [22]. Other staff may need to be redeployed and receive training in the management of critical care patients to support fully trained staff, permitting a dilution of the standard critical care nurse to patient ratio [23]. Flexibility around dependency level and staff experience will be required [24]. The expansion of ICU capacity to provide critical care in other areas will require the pre-emptive identification, tracing and maintenance of all usable equipment and potentially the stockpiling of key items to allow for rapid up-scaling of activity in response to demand.

It is likely that there will be some variability in the prevalence of influenza across the country during a pandemic wave, with peaks in demand staggered across geographical areas. It may be possible to disperse some of the patient load by interfacility transfer if this occurs to any significant extent.

The expansion of ICU facilities during the SARS epidemic in Hong Kong and Singapore was recently described [25]. Infection control is recognised as an overriding priority for the delivery of critical care, including the ability, in the early stages, to cohort cases. This should ideally include the use of separate entrances and exits, isolation rooms with negative pressure ventilation and dedicated separate healthcare staff. The Toronto experience identified 21 secondary cases of nosocomial transmission of SARS in ICU from an initial index case before infection control measures were introduced. Even following the introduction of extensive protective equipment, nine healthcare workers developed SARS as a result of being present in the room during the intubation of a single patient. In terms of personal protection, planning and practice in the donning of protective equipment (PPE) and prior fit testing is essential [26]. The practicalities of being able to manage patients when fully attired must be understood and consideration given to the fact that any procedure or task will take longer. This will impact on care efficiency and the staff to patient ratio.

While beds can be scaled up and extra areas recruited to provide critical care, without trained staff the planning will be ineffective. Staff illness rates and the risk to staff must be factored into the planning process. In the UK, staff illness has been estimated at $30 \%$ with work absences of up to 8 days [2]. Normal working patterns may need to be revised and facilities provided for staff to stay on site rather than go home to their families. Staff absence tends to be greater the longer special circumstances apply and the greater the impact on the lives of the staff [27]. The preventive effectiveness of neuraminidase inhibitors may make focussed chemoprophylaxis a strategy for reducing staff illness in critical care areas [28].

\section{Triage}

The evolution of a new pandemic strain of influenza will inevitably result in a major increase in demand for critical care services. It is likely that these services will rapidly reach their 
capacity and even their contingency arrangements for extended facilities will be overwhelmed. Excessive demand where resources are finite creates an ethical dilemma and many emergency plans apply a utilitarian approach of 'best care for the greatest number' [29]. There is a legitimate debate about how limited capacity can best be utilised, but a number of themes are recurrent. There needs to be a legal and ethical framework for the process decided in advance, the rationale for triage should be fair and transparent and it should meet the principles of distributive justice [30-32]. Triage can conflict with human rights legislation and even humanitarian laws but 'accountability for reasonableness' can temper the disagreements about priority setting [33].

The decision making process needs to be valid and reproducible. Although there are a number of triage systems available for mass casualty incidents, there has been little validation of any of them in the field [34], and what there has been relates to 'big bang' single incidents and the apparent unreliability of triage $[35,36]$. While it does not need to be explicit ahead of time, the decision thresholds should be based on both the cumulative evidence about the disease process and prognosis, and the number of patients and severity of illness making the demands on the service [31]. In effect, triage may result in a gradual degradation of care with the increasing scale of the incident and become a 'societally mandated Do Not Resuscitate order'. On these grounds the process needs to be carefully considered at an appropriately senior level and applied consistently [32].

Allowing for the utilitarian approach, it is recognised that in mass casualty incidents, the standard of care for all patients, including those not immediately related to the incident, may need to be adjusted and reduced. While this may infringe individual rights, the higher ethical principle of 'wellness of society as a whole' allows for the direction of resources to those where it is felt most effective. It may also allow for an expansion in the scope of practice of non-physicians [37].

It may be unrealistic and impractical to expect that senior medical intensive care staff will make all decisions regarding instituting critical care and there will be a need to empower more referring general clinicians to do so. This is at odds with the need for decision making by the most senior person [32] and will require a change in practice for many clinicians; it is not current practice in the UK. The use of track and triage protocols will be essential to direct this decision making and ensure its consistency. Ardagh [38] has developed a set of pragmatic questions for the clinician facing acute problems of resource allocation; the only point lacking in his assessment process is a tool for the 'ranking' of patients in terms of likelihood of benefit from the limited resources.

We believe that the basic criteria for a system for triage to critical care in a pandemic are fourfold; it should identify patients sick enough to require higher level care at some stage in their illness, it should be able to recognise those patients who are too acutely or chronically unwell to benefit from critical care, it should be consistently applicable by healthcare professionals and support workers from a variety of backgrounds within the constraints of the pandemic and should ideally also be scalable to reflect any mismatch between need and capacity. In order to fairly allocate resources across both flu and non-flu patients it should also be disease non-specific and allow prognostic comparisons across disease categories.

A number of scoring systems have been advocated for use in a pandemic. The UK Department of Health currently recommends a six-point pneumonia severity score [2]. Although US guidelines emphasise the importance of triage in primary influenza, specific tools are only recommended for assessment of post-influenza bacterial pneumonia [39].

The majority of available potential scores were developed as mortality indicators and perform less well for predicting critical care usage. Amongst ICU admissions with community-acquired pneumonia in Massachusetts in 1996 to 1997, 10/32 scored CURB-65 1 or 2 (that is, low risk) and 5/32 were classified as PSI (Pneumonia Severity Index) class III (intermediate risk) [40]. Even amongst patients with pneumonia included in the PROWESS study, only $90.5 \%$ were PSI class IV or V, and only $70.3 \%$ had a CURB-65 score of 3 or above [41].

There is no guarantee that pandemic influenza will be primarily pneumonic in its presentation; case reports have documented $\mathrm{H} 5 \mathrm{~N} 1$ influenza presenting with diarrhoea $[42,43]$ and coma [43] and a World Health Organisation summary has described absence of respiratory symptoms in a number of cases [44]. The utility of disease-specific pneumonia scores may also be limited by mortality from comorbidities such as cardiovascular disease.

A number of intensive care scoring systems have demonstrated their power in using physiological derangement to predict mortality or higher resource requirements, whatever the presenting diagnosis [45-49]. Physiological scores have also been demonstrated to be good predictors of requirement for higher level care on hospital wards [50], in medical assessment units $[51,52]$ and in the Emergency Department [53]. We have demonstrated that a purely clinical score incorporating acute physiological derangement and chronic health and performance status can reliably predict requirement for critical care [54].

It is inevitable that if an influenza pandemic reaches the scale of some predictions, some patients who, in normal circumstances, would benefit from critical care will not be offered it. Critical care triage will need to evolve from a process of identifying cases who need high level care to one that determines those patients most likely to benefit from the 
limited resources available and distinguishes them from those where care is likely to be futile.

This is recognised by the Emergency Medicine community and the US administration in terms of disaster triage [37,55]. The American Thoracic Society adopted the utilitarian principle a decade ago, stating that "the duty of health providers to benefit an individual patient has limits when doing so unfairly compromises the availability of resources needed by others" [56]. The problem now facing policymakers and clinicians is defining a process for resource allocation that meets the requirements of distributive justice and accountability for reasonableness [33]. As the Working Group on Emergency Mass Critical Care of the Society for Critical Care Medicine recognised, "an ideal triage system is based on data collected at hospital admission, requires little or no laboratory testing, and has been proven to predict hospital survival" [57].

The Ontario Ministry of Health Long-term Care working group have courageously taken the first steps in defining a triage protocol for critical care [58] and their use of serial Sequential Organ Failure Assessment (SOFA) scores to place a ceiling on care provided to non-responding patients is to be supported. However, it is unlikely to be feasible for all patients to have a trial of inotropes and/or ventilation and some way of screening out the sicker patients at ward/floor level will be required.

We are not aware of the use of objective prognostic scores to allocate or refuse critical care resources at present and indeed most research demonstrates the ad hoc nature of admission decision-making [59]. However, if, as is likely, review by experienced critical care physicians is impractical, decision support will be required for the non-critical care specialist. Emergency physicians, for example, had a positive predictive value (PPV) of only $73 \%$ in identifying those with a low chance of survival, as opposed to critical care fellows (PPV 83\%) and the Mortality Probability Model (MPM ; PPV 86\%) [60].

SOFA scoring has previously been demonstrated on a multinational basis to predict high risk of mortality (a SOFA score of over 15 was $98.9 \%$ specific for mortality) [61]. Other critical care scoring systems show comparable performance in mortality prediction; discrimination as measured by area under Receiver Operator Characteristic (ROC) curve was 0.825 to 0.901 for Acute Physiology and Chronic Health Evaluation III (APACHE III) [62-65], 0.79 to 0.846 for Simplified Acute Physiology Score II (SAPS II) [62,64,66], and 0.928 for the Multiple Organ Dysfunction Score [67]. However, calibration of these scores to give absolute risks of mortality has not always been reliable [65] and has required customisation for international use $[68,69]$.

Concentrated work is clearly required to amend and validate existing scoring systems so that they are suitable for use as triage tools. We suggest that this should be done on two levels. While disease specific scoring systems are valuable and should continue to be refined, there is a need to develop an appropriately generalisable scoring system for as unselected a group of patients as possible. To have the discriminating power, it will need to take place on a multicentre or, preferably, on a multi-national basis.

\section{Conclusion}

It is a general principle of major incident planning that procedures should not be changed at precisely the moment when the system or institution is under its greatest stress, so planning for pandemic flu needs to make use as much as possible of systems and procedures already in place. Development of a triage system and tool needs to be accompanied by planning for hospital command and control (to dictate scalability as related to available resources) and by training for staff whose roles may change.

Researchers, clinicians and policymakers in the field need to analyse systems and scores already in existence and improve and validate them as triage tools (though this may not be the purpose for which they were originally developed). At the same time ethical principles require transparency and consistency in the decision-making process, and involvement of public in its development.

In reality, perhaps the question we need to address is the action required when critical care services are overwhelmed. The scalability of triage tools may aid in decision making by objectively altering the threshold for admission to critical care. However, the time may come when we need realistically to evaluate the effectiveness of critical care in influenza. If survival with the benefit of critical care is marginal (for example, $<10 \%$ ) and there is a significant cross-infection risk, perhaps critical care should then close and concentrate its efforts on outreach to other areas, including wards. Direction and support from professional bodies and health departments will be required to support the medical staff with such difficult decisions possibly against a ground swell of media-driven public opinion.

\section{Competing interests}

DW is a member of the UK Department of Health Critical Care Contingency Planning Working Group. The other authors declare that they have no competing interests.

\section{This article is part of a thematic series on Disaster management edited by J Christopher Farmer.}

Other articles in this series can be found online at http://ccforum.com/articles/

theme-series.asp?series=CC_Disaster 


\section{References}

1. Health Protection Agency: Influenza Pandemic Contingency Plan (2005) [http://www.hpa.org.uk/infections/topics_az/influenza/ pandemic/pdfs/HPAPandemicplan.pdf]

2. UK Health Departments' UK Influenza Pandemic Contingency Plan (October 2005)

[http://www.dh.gov.uk/PublicationsAndStatistics/Publications/ PublicationsPolicyAndGuidance/

PublicationsPolicyAndGuidanceArticle/fs/ en?CONTENT_ID=4121735\&chk=Z6kjOY]

3. United States Department of Health and Human Services: Pandemic Influenza Plan (2006) [http://www.hhs.gov/pandemicflu/ plan]

4. Hick JL, Hanfling D, Burstein JL, DeAtley C, Barbisch D, Bogdan GM, Cantrill S: Health care facility and community strategies for patient care surge capacity. Ann Emerg Med 2004, 44:253261.

5. Centers for Disease Control and Prevention: FluSurge [http://www.cdc.gov/flu/tools/flusurge/]

6. Menon D, Taylor B, Ridley S: Modelling the impact of an influenza pandemic on critical care services in England. Anaesthesia 2005, 60:952-954.

7. Challen K, Walter D: Accelerated discharge of patients in the event of a major incident: observational study of a teaching hospital. BMC Public Health 2006, 6:108.

8. Davis DP, Poste JC, Hicks T, Polk D, Rymer TE, Jacoby I: Hospital bed surge capacity in the event of a mass-casualty incident. Prehospit Disast Med 2005, 20:169-176.

9. Kelen GD, Kraus CK, McCarthy ML, Bass E, Hsu EB, Li G, Scheulen JJ, Shahan JB, Brill JD, Green GB: Inpatient disposition classification for the creation of hospital surge capacity: a multiphase study. Lancet 2006, 368:1984-90.

10. Halpern P, Tsai M, Arnold J, Stok E, Ersoy G: Mass-casualty, terrorist bombings: implications for emergency department and hospital emergency response (Part II). Prehosp Disast Med 2003, 18:235-241.

11. Levi L, Bregman D, Geva H, Revach M: Hospital disaster management simulation system. Prehosp Disast Med 1998, 13:2934.

12. Areechokchai $D$, Jiraphongsa $C$, Laosiritaworn $Y$, Hanshaoworakul W, O'Reilly M: Investigation of avian influenza (H5N1) outbreak in humans - Thailand, 2004. Mortal Morbid Week Rep 2006, 55(S1):3-6.

13. Booth CM, Stewart TE: Severe acute respiratory syndrome and critical care medicine: The Toronto experience. Crit Care Med 2005, 33:S53-60.

14. Department of Health: NHS Emergency Planning Guidance (2005)

[http://www.dh.gov.uk/PublicationsAndStatistics/Publications/ PublicationsPolicyAndGuidance/

PublicationsPolicyAndGuidanceArticle/fs/ en?CONTENT_ID=4121072\&chk=yCJURO]

15. Tsai M-C, Arnold JL, Chuang C-C, Chi C-H, Liu C-C, Yang Y-J: Implementation of the hospital emergency incident command system during an outbreak of severe acute respiratory syndrome (SARS) at a hospital in Taiwan, ROC. J Emerg Med 2005, 28:185-196.

16. Joint Commission on Accreditation of Healthcare Organizations: Health Care at the Crossroads. Washington DC: JCAHO; 2003.

17. Standards Australia: Planning for Emergencies - Health Care Facilities. Homebush NSW: Standards Australia; 1997.

18. Carli P, Telion C, Baker D: Terrorism in France: the medical response. Prehosp Disast Med 2003, 18:92-99.

19. Centre for Excellence in Emergency Preparedness: General Readiness Checklist: a Template for Healthcare Facilities. Toronto: CEEP; 2006.

20. Hsu EB, Thomas TL, Bass EB, Whyne DM, Kelen GD, Green GB: Healthcare worker competencies for disaster training. $B M C$ Med Educ 2006, 6:19.

21. Delooz H, Debacker M, Moens G, Johannik K: European survey on training objectives in disaster medicine. Eur $J$ Emerg Med 2007, 14:25-31.

22. Department of Health: Critical Care Contingency Planning in the Event of an Emergency Where the Number of Patients Substantially Exceeds Normal Critical Care Capacity http://www.dh.gov.uk/en/Consultations/Closedconsultations/ DH 064169
23. Toner $E$, Waldhorn R: What hospitals should do to prepare for an influenza pandemic. Biosec Bioterror 2006, 4:397-402.

24. Sawadsky B: Surge Capacity. In Proceedings of the International Congress on Emergency Medicine: June 3-7 2006; Halifa, Nova Scotia, Canada. Ottawa: Canadian Association of Emergency Physicians; 2006.

25. Gomersall CD, Tai DYH, Loo S, Derrick JL, Goh MS, Buckley TA, Chua C, Ho KM, Raghavan GP, Ho OM, et al:: Expanding ICU facilities in an epidemic: recommendations based on experience from the SARS epidemic in Hong Kong and Singapore. Intensive Care Med 2006, 32:1004-1013.

26. Gamage B, Moore D, Copes R, Yassi A, Bryce E: Protecting health care workers from SARS and other respiratory pathogens: A review of the infection control literature. $\mathrm{Am} J$ Infect Control 2005, 33:114-121.

27. Wise R: The creation of emergency health care standards for catastrophic events. Academic Emerg Med 2006, 13:1150-1152.

28. Turner D, Wailoo A, Nicholson K, Cooper N, Sutton A, Abrams K: Systematic review and economic decision modelling for the prevention and treatment of influenza A and B. Health Technol Assess 2003, 7:1-170.

29. Bar-Joseph G, Michaelson M, Halberthal M: Managing mass casualties. Curr Opin Anesthesiol 2003, 16:193-199.

30. Mehta S: Disaster and mass casualty management in a hospital: How well are we prepared? J Postgrad Med 2006, 52:89-90.

31. Saffle J, Gibran N, Jordan M: Defining the ratio of outcomes to resources for triage of burn patients in mass casualties. J Burn Care Rehab 2005, 26:478-482.

32. Sztajnkrycer M, Madsen B, Baez A: Unstable ethical plateaus and disaster triage. Emerg Med Clin North Am 2006, 24:749768.

33. Daniels N: Accountability for reasonableness. BMJ 2000, 321: 1300-1301.

34. Cone DC, MacMillan DS: Mass-casualty triage systems: a hint of science. Academic Emerg Med 2005, 12:739-741.

35. Ashkenazi I, Kessel B, Khashan T, Haspel J, Oren M, Olsha O, Alfici R: Precision of in-hospital triage in mass-casualty incidents after terror attacks. Prehosp Disast Med 2006, 21:20-23.

36. Ceballos JPGd, Fuentes FT, Diaz DP, Sanchez MS, Llorente CM, Sanz JG: Casualties treated at the closest hospital in the Madrid, March 11, terrorist bombings. Crit Care Med 2005, 33: S107-S112.

37. Agency for Healthcare Research and Quality: Altered Standards of Care in Mass Casualty Events. Rockville: Agency for Healthcare Research and Quality; 2005.

38. Ardagh $M$ : Criteria for prioritising access to healthcare resources in New Zealand during an influenza pandemic or at other times of overwhelming demand. NZ Med J 2006, 119: U2256.

39. United States Department of Health and Human Services: Pandemic Influenza Plan - Clinical Guidelines [http://www.hhs.gov/pandemicflu/plan/sup5.html]

40. Smyrnios NA, Schaefer OP, Collins RM, Madison JM: Applicability of prediction rules in patients with community-acquired pneumonia requiring intensive care: a pilot study. J Intensive Care Med 2005, 20:226-232.

41. Laterre P-F, Garber G, Levy $H$, Wunderink R, Kinasewitz GT, Sollet J-P, Maki DG, Bates B, Yan SCB, Dhainaut J-F: Severe community-acquired pneumonia as a cause of severe sepsis: Data from the PROWESS study. Crit Care Med 2005, 33:952961.

42. Apisarnthanarak $A$, Kitphati $R$, Thongphubeth $K$, Patoomanunt $P$, Anthanont P, Auwanit W, Thawatsupha P, Chittaganpitch M, Saeng-Aroon S, Waicharoen $\mathrm{S}$, et al:: Atypical avian influenza (H5N1). Emerging Infect Dis 2004, 10:1321-4.

43. de Jong MD, Van Cam B, Qui PT, Hien VM, Thanh TT, Hue NB, Beld M, Phuong LT, Khanh TH, Chau NVV, et al.: Fatal avian influenza $A(\mathrm{H} 5 \mathrm{~N} 1)$ in a child presenting with diarrhea followed by coma. N Engl J Med 2005, 352:686-691.

44. Writing Committee of the World Health Organization (WHO) Consultation on Human Influenza A/H5: Avian influenza A (H5N1) infection in humans. N Engl J Med 2005, 353:13741385.

45. Zimmerman JE, Kramer AA, McNair DS, Malila FM: Acute Physiology and Chronic Health Evaluation (APACHE) IV: Hospital mortality assessment for today's critically ill patients. Crit Care Med 2006, 34:1297-1310. 
46. Castella X, Artigas A, Bion J, Kari A: A comparison of severity of illness scoring systems for intensive care unit patients: results of a multicenter, multinational study. Crit Care Med 1995, 23:1327-1335.

47. Fagon J-Y, Chastre J, Novara A, Medioni P, Gibert C: Characterization of intensive care unit patients using a model based on the presence or absence of organ dysfunctions and/or infection: the ODIN model. Intensive Care Med 1993, 19:137-144.

48. Le Gall J-R, Loirat P, Alperovitch A: Simplified acute physiological score for intensive care patients. Lancet 1983, 2:741.

49. Moreno R, Vincent J-L, Matos R, Mendonça A, Cantraine F, Thijs L, Takala J, Sprung C, Antonelli M, Bruining H, et al.: The use of maximum SOFA score to quantify organ dysfunction/failure in intensive care. Results of a prospective, multicentre study. Intensive Care Med 1999, 25:686-696.

50. Goldhill D, McNarry A, Mandersloot G, McGinley A: A physiologically-based early warning score for ward patients: the association between score and outcome. Anaesthesia 2005, 60: 547-553.

51. Kellett J, Deane B: The Simple Clinical Score predicts mortality for $\mathbf{3 0}$ days after admission to an acute medical unit. Quart $J$ Med 2006, 99:771-781.

52. Subbe C, Kruger M, Rutherford P, Gemmell L: Validation of a modified early warning score in medical admissions. Quart $J$ Med 2001, 94:521-526.

53. Shapiro N, Howell MD, Bates DW, Angus DC, Ngo L, Talmor D: The association of sepsis syndrome and organ dysfunction with mortality in emergency department patients with suspected infection. Ann Emerg Med 2006, 48:583-590.

54. Challen K, Bright J, Bentley A, Walter D: Physiological-social score (PMEWS) vs. CURB-65 to triage pandemic influenza: a comparative validation study using community-acquired pneumonia as a proxy. BMC Health Serv Res 2007, 7:33.

55. Burkle FJ: Population-based triage management in response to surge-capacity requirements during a large-scale bioevent disaster. Academic Emerg Med 2006, 13:1118-1129.

56. American Thoracic Society Bioethics Task Force: Fair allocation of intensive care unit resources. Am J Resp Crit Care Med 1997, 156:1282-1301.

57. Rubinson L, Nuzzo JB, Talmor DS, O'Toole T, Kramer BR, Inglesby TV: Augmentation of hospital critical care capacity after bioterrorist attacks or epidemics: Recommendations of the Working Group on Emergency Mass Critical Care. Crit Care Med 2005, 33(Suppl):E2393.

58. Christian MD, Hawryluck L, Wax RS, Cook T, Lazar NM, Herridge MS, Muller MP, Gowans DR, Fortier W, Burkle FM: Development of a triage protocol for critical care during an influenza pandemic. Canadian Med Assoc J 2006, 175:1377-1381.

59. Mielke J, Martin DK, Singer PA: Priority setting in a hospital critical care unit: Qualitative case study. Crit Care Med 2003, 31: 2764-2768

60. Rodriguez RM, Wang NE, Pearl RG: Prediction of poor outcome of intensive care unit patients admitted from the emergency department. Crit Care Med 1997, 25:1801-1806.

61. Vincent J-L, de Mendonca A, Cantraine F, Moreno R, Takala J, Suter P, Sprung CL, Colardyn F, Blecher S: Use of the SOFA score to assess the incidence of organ dysfunction/failure in intensive care units: results of a multicenter prospective study. Crit Care Med 1998, 26:1793-1800.

62. Markgraf R, Deutschinoff G, Pientka L, Scholten T: Comparison of acute physiology and chronic health evaluations II and III and Simplified Acute Physiology Score II: a prospective cohort study evaluating these methods to predict outcome in a German interdisciplinary intensive care unit. Crit Care Med 2000, 28:26-33.

63. Pettilä V, Pettilä M, Sarna S, Voutilainen P, Takkunen O: Comparison of multiple organ dysfunction scores in the prediction of hospital mortality in the critically ill. Crit Care Med 2002, 30: 1705-1711.

64. Reina A, Vazquez G, Aguayo E, Bravo I, Colmenero M, Bravo M: Mortality discrimination in acute myocardial infarction: comparison between APACHE III and SAPS II prognosis systems. Intensive Care Med 1997, 23:326-330.

65. Sirio CA, Shepardson LB, Rotondi AJ, Cooper GS, Angus DC, Harper DL, Rosenthal GE: Community-wide assessment of intensive care outcomes using a physiologically based prognostic measure. Chest 1999, 115:793.
66. Sicignano A, Carozzi C, Giudici D, Merli G, Arlati S, Pulici M: The influence of length of stay in the ICU on power of discrimination of a multipurpose severity score (SAPS). Intensive Care Med 1996, 22:1048-1051.

67. Marshall JC, Cook DJ, Christou NV, Bernard GR, Sprung CL, Sibbald WJ: Multiple Organ Dysfunction Score: a reliable descriptor of a complex clinical outcome. Crit Care Med 1995, 23:1638-1652.

68. Goldhill D, Withington P: The effect of casemix adjustment on mortality as predicted by APACHE II. Intensive Care Med 1996, 22:415-419.

69. Apolone G, Bertolini G, D'Amico R, lapichino G, Cattaneo A, De Salvo G, Melotti RM: The performance of SAPS II in a cohort of patients admitted to 99 Italian ICUs: results from GiViTI. Intensive Care Med 1996, 22:1368-1378. 